\title{
A synthesis of the evidence on peer-research with potentially vulnerable adults: how this relates to dementia
}

\section{Claudio Di Lorito ${ }^{1}$, Linda Birt ${ }^{2}$, Fiona Poland ${ }^{2}$, Emese Csipke ${ }^{3}$, Dianne Gove ${ }^{4}$, Ana Diaz-Ponce ${ }^{4}$ and Martin Orrell ${ }^{1}$}

${ }^{1}$ Division of Psychiatry and Applied Psychology, School of Medicine, University of Nottingham, Nottingham, United Kingdom.

${ }^{2}$ School of Health Sciences, Faculty of Medicine and Health Sciences, University of East Anglia, Norwich, United Kingdom.

${ }^{3}$ Division of Psychiatry, University College London, London, United Kingdom.

${ }^{4}$ Alzheimer Europe, Luxembourg.

Corresponding author: Claudio Di Lorito, Division of Psychiatry \& Applied Psychology, School of Medicine, University of Nottingham, Nottingham, NG7 2TU, United Kingdom. Email: claudio.dilorito@nottingham.ac.uk 


\section{Abstract}

Background. There is limited literature around peer-research in dementia. This study aims to identify the benefits, the risks and the practical challenges and to develop a model of goodpractice in peer-research with people with dementia.

Methods. We searched on PsycInfo, PubMed and Google Scholar for empirical investigations or discussion papers on peer-research. Given the limited literature in the field of dementia, we included studies with groups who share similar demographics (older people), experience of stigma (mental health service users) and exclusion from research (people with learning disabilities). We applied no restrictions on language and publication date.

Analysis. We identified three themes: the potential benefits, the potential risks and the practical challenges of peer-research. We developed a model of good practice. The European Working Group of People With Dementia (EWGPWD) reviewed our paper and added to our findings.

Results. We included 7 papers. Potential benefits of peer-research included enriched data and empowering people with dementia. Potential risks included power differentials between researchers and issues of representativeness. The practical issues for good practice included the training of peer-researchers, defining involvement and roles, working with cognitive impairment and considering resource implications. The EWGPWD emphasised the importance of equality issues.

Conclusion. Involving people with dementia in peer-research can generate several benefits, including empowerment and opportunities for inclusion for the peer-researchers and the research participants living with dementia, challenging academics' traditional views on research processes and gathering enhanced research data. There remains a need for further research on the impact of peer-research in dementia studies. 


\section{Key points:}

- Peer-research with people with dementia is a novel type of PPI and limited literature exists at present time. To our knowledge, our review is the first one reporting on peerresearch with people with dementia.

- Our findings suggest that peer-research with people with dementia is feasible and that it can generate potential benefits for the peer-researchers, the academic researchers, the participants to the study and the research project.

- Some challenges and practical issues need to be addressed in order to maximise peerresearch. These include offering training of peer-researchers, defining involvement and roles, working effectively with cognitive impairment and considering resource implications.

- Issues of equality and human rights, which have been so far neglected in the literature around peer-research with people with dementia, need to be crucially addressed.

Keywords: Co-research, dementia, participatory research, patient and public involvement, peer-research.

Running title: Peer-research with potentially vulnerable adults. 


\section{Introduction}

Peer-research, also known as co-research, is a specific type of public and patient involvement (PPI) where patients undertake research activities such as data collection or analysis alongside academics. Peer-research is different from other types of PPI such as participating in committees, consulting on information sheets and being involved in consensus workshops, as it gives people with experience of the condition the opportunity to work alongside academics in all stages of empirical research (Frankham, 2009; Repper et al., 2007; Staley, 2009; Turner and Beresford, 2005).

While there have been advances in the practice of patient involvement, empirical literature reporting peer-research with people with dementia remains scarce, as societal stigma has traditionally silenced the voices of people living with dementia and confined them to the role of research participants (Wilkinson, 2002; Wilkinson and Hubbard, 2003). Peer-research with other populations of service users such as people with learning or intellectual disabilities seems to be at a more advanced stage and it may be that researchers are limited by conceptions that a person with dementia lacks the cognitive ability to be involved in complex research activities, like working with analytical concepts or engaging effectively with the public (Dewing, 2002; Downs, 1997; Moore and Hollett, 2003). However, Bartlett's (2014) pioneering work exploring the experiences of people with dementia involved in campaigning for social justice suggests that this preconception is unfounded.

The aim of this paper was to explore how research studies have worked with people with dementia as peer-researchers, to identify the potential risks and benefits of peer-research, to explore its practical aspects and to develop a model of good practice in peer-research. 


\section{Methods}

\section{Electronic searches}

Given the paucity of studies on peer-research with people with dementia, to supplement our data we extended our investigation to studies reporting peer-research with other populations of service users who share similar characteristics with people with dementia such as demographics (older people), experience of stigma (mental health service users) and exclusion from research (people with learning disabilities). While urging caution in interpreting our results, given the evident differences between these populations, we felt that these populations may experience similar challenges as people with dementia in terms of exclusion from research and that therefore their experience of peer-research may well inform and supplement our review.

To ensure that we captured appropriate papers for this synthesis, we undertook a structured literature search. We searched PsycInfo, PubMed and Google Scholar for the following terms: ("peer-research*” or "co-research*” or "participat* research*” or "involv*”) and (“dementia" or "learning difficulties" or "older people" or "mental health service user*”). We did not apply any restrictions on the year of publication and on language, as we aimed to review the status of peer-research in dementia at the international level. Given the limited literature on peer-research, we did not exclude any study on the grounds of methodological quality. However, to get a sense of the quality of the studies included in the review, two authors (CDL and LB) rated the papers independently with an overall quality score.

\section{Inclusion criteria}

1. Focuses on health and social care research and is an empirical investigation or a discussion paper on peer-research.

2. Includes people with dementia, older people, mental health service users and/or people with learning disabilities working as peer-researchers. 


\section{Data extraction and analysis}

We extracted data that was relevant to answer our research questions and synthesised them in three themes: the potential benefits and challenges for peer-researchers, participants, academic researchers and the research data and the practical considerations of working with people with dementia as peer-researchers. Based on the findings from the latter theme, we developed our model for good practice in peer-research with people with dementia.

\section{Consultation with the European Working Group of People With Dementia (EWGPWD)}

We presented our results to the European Working Group of People With Dementia (EWGPWD). The EWGPWD was set up by Alzheimer Europe and is composed of eight people with dementia from different countries around Europe who collaborate with the organisation to ensure that its projects are relevant for people with dementia. The members of the group have lived experience of peer-research at the national or international level.

In line with our principles of meaningful involvement in research, we asked the EWGPWD to comment on how relevant for people with dementia our findings are and to provide their comments to be integrated within our results.

\section{Results}

The search retrieved 51 studies, which were appraised by two independent reviewers (CDL and LB). Following title or abstract review, 44 papers were excluded, as they did not meet the inclusion criteria (Figure 1). Seven papers met the inclusion criteria and were selected for full review (Table 1).

All papers employed qualitative methodologies, which seems to be the paradigm most often used in peer-research. One article evaluated the experiences of people with dementia working as peer-researchers (Tanner, 2012). Another article reported core principles of service-userled research and was developed by a working group of people with dementia (Scottish Dementia Working Group, 2014), while the remaining five addressed peer-research with 
older people, mental health service users and people with learning difficulties. Among these five papers, one was an empirical evaluation of the experience of being an older person peerresearcher (Littlechild et al., 2015) while the remaining four are discussion papers about the practice of working with peer-researchers.

\section{The potential benefits of working with peer-researchers (Table 2)}

Peer-researchers. Our analysis evidenced that peer-research may generate several benefits. Peer-researchers stated that they felt they were contributing to improving services for people with dementia (Littlechild et al., 2015) and Tanner (2012) believed that the opportunity for social involvement could help reduce the sense of isolation and stigma attached to dementia.

Participants. Evident across the studies was that research participants may also benefit from peer-research. The opportunity to meet with peers who promote a positive image of dementia may facilitate the participant's transition process to a new post-diagnosis identity and improve life quality (Tanner, 2012).

Academic researchers. For academics, peer-research may ease the understanding of living with dementia in a wider and more directly experienced sense than that captured in the traditional research process (Tanner, 2012). As Clough et al. (2006) stated:

'Insights derived from direct personal experience, unmediated by entrenched professional positions, will add value to your outputs.'

Research data. Working with peer-researchers can enhance the study. Involving peerresearchers can boost recruitment rates, given the social contacts of people with dementia within their community and this is particularly valuable for hard-to-reach populations, who are traditionally under-represented in research (Littlechild et al., 2015). Involving peerresearchers may also increase the depth of the data collected. Peer-researchers can encourage research participants to give more personal responses, as they tend to adopt a more informal 
approach to interviewing and show a greater ability to empathise, drawing on their own lived experience with dementia (Littlechild et al., 2015; Tanner, 2012).

\section{The Challenges of working with peer-researchers (Table 2).}

Selecting representative peer-researchers. The academic team needs to consider how much the peer-researchers are actual peers of those being interviewed, in other words whether peerresearchers mirror the diversity of the community of people with dementia. Tanner (2012) suggested that peer-research is feasible in practice only with people at early stage dementia, yet only involving users within this sub-group would exclude the voices of individuals at later stage dementia. This same issue may arise if peer-researchers are selected to share a similar background with participants. Although Tanner (2012) suggested that participants may open up more easily with interviewers they can relate to, a homogeneous sample would not mirror the diversity in race, gender, age and personality of people with dementia (Littlechild et al., 2015).

Negotiating research power. Another challenge concerns the negotiation of power between researchers, which was well documented in several papers (Rose, 2003; Miller, 2006;

Littlechild et al., 2015, Clough et al., 2006). Some academics may be reluctant to cede control to peer-researchers and/or delegate to them more complex research tasks such as handling sensitive information or assessing capacity to consent (Miller, 2006; Littlechild et al., 2015). On the other hand, peer-researchers may feel they are constrained in a strictly hierarchical relationship that is also reflected in salary differences (Rose, 2003). In order to facilitate the process of involvement, academics should re-evaluate the concept of partnership and commit to fully involve peer-researchers, in order to avoid the type of one-off consultation that would give the impression that academics only want to tick the user-involvement box (Rose, 2003; Clough et al., 2006). 


\section{The practical considerations of working with people with dementia as peer-researchers}

Training. Training of peer-researchers was identified as essential in all papers. Offering practical research training represents an invaluable opportunity for the peer-researchers to develop their research skills and familiarise with a project (Tanner, 2012). Research training could also be instrumental for peer-researchers to develop their confidence to take on the responsibility of doing research (Rose, 2003), to become aware of their own capacities and limits, to understand the context of social research and the practicalities of the study (Clough et al., 2006) and to discuss the questionnaire and exercise interviewing skills (Tanner, 2012). Given that dementia can be experienced very differently among different individuals, the training sessions should be tailored to the peer-researcher's needs in order to maximise results (Scottish Dementia Working Group, 2014). Beyond building research skills through training, Miller et al. (2006) suggested that peer-researchers should ideally possess good social skills, such as being able to empathise, listen actively and communicate effectively (including nonverbally), as these qualities will help gather enriched narratives in the interview sessions.

Defining involvement and roles. In our analysis it emerged that defining each researcher's involvement and role at the initial stage of collaboration helps create the conditions for effective involvement of peer-researchers. The extent of the involvement of service users in research depends on several factors: it may mirror the directives of funders (Miller, 2006), the academic team's belief of how much peer-researchers can 'enhance the research' (Miller, 2006), but it is also based on pragmatic issues. Walmsley (2004) urged caution when defining service users' roles in research, stressing the need to acknowledge the cognitive impairment of some groups and therefore to be realistic about the extent of involvement, so that research quality is not compromised. Once the extent of involvement has been defined, Miller (2006) suggested that an open discussion about the roles, responsibilities and expectations of academic and peer-researchers is essential to develop a relationship of trust and mutual respect with service users who may take on a research role. The discussion should ideally 
continue throughout involvement, as research roles should be flexible and renegotiable according to the presenting circumstances (Miller, 2006).

Cognitive impairment. A particular challenge in peer-research is cognitive impairment, which may present difficulties in carrying out some research tasks (Scottish Dementia Working Group, 2014). These however can be addressed with some simple strategies so that the input of peer-researchers can be optimised (Scottish Dementia Working Group, 2014). These strategies include using simple and jargon-free language, reducing abstract language or concepts, considering non-verbal language as a valid communication tool, avoiding making assumptions, resisting the temptation to finish the peer-researcher's sentences and maintaining a relaxed and unhurried attitude (Tanner, 2012).

Memory difficulties. Memory difficulties can be overcome by using visual prompts such as laminated cards to aid the peer-researchers during the administration of interview questions (Tanner, 2012). Pre and post-interview briefing and debriefing discussions between researchers to revise interview questions may also be helpful (Tanner, 2012). On the day of the interview, meeting the peer-researcher in a familiar environment or sharing the journey to the interview could also represent an opportunity to review the details of the study, strengthen the trust and working relationships, and facilitate co-operation during the interview session (Tanner, 2012).

Location of involvement. Location requires careful consideration. For example, the physical environment of universities may present challenges to people with cognitive impairment, who may perceive it as more threatening than their homes or public spaces, which can more easily accommodate their complex needs (Littlechild et al., 2015).

Emotional stress. The research team should pay attention to the risk of emotional overburden that may affect the peer-researchers' wellbeing during involvement. The Scottish Dementia Working Group (2014) strongly recommended that the research team make some form of 
counselling and emotional support available to peer-researchers, who may feel distressed when hearing their peers' stories during the interview sessions.

Resource implications. Adopting good practice in peer-research can significantly increase research costs due to providing training or financially compensating peer-researchers, to refunding travel expenses or to paying support workers to accompany the peer researchers on research activities (Littlechild et al., 2015). Given the inevitable additional costs, the research team should aim to pursue high-quality involvement so that the added value of peer-research matches its economic implications (Walmsley, 2004). As the investment of time and resources needs to be optimised, there should be effective evaluation of the practical aspects of working with peer-researchers alongside an evaluation of the benefits and challenges.

\section{Consultation with the European Working Group of People With Dementia (EWGPWD)}

The findings presented in this section represent a summary of the EWGPWD consultation report. Details are reported in tables 2 and 3.

The members of the EWGPWD felt enthusiastic about our review, which investigates a type of involvement that is felt as crucial for the empowerment of people with dementia. There were mixed views on our choice to include in the review other populations of service users, who for some have a different experience of living with their conditions compared to people with dementia. Overall however, the group appreciated the rationale behind our decision.

Equality and self-determination among members of the research team were felt as fundamental conditions for meaningful involvement, as highlighted by two member of the EWGPWD:

'You want that person not be made to feel different in their role in the research team'.

'As people with dementia, we still have the right to make our own choice and if we choose to be tired and we want to put our health at risk to be involved in this research, we have the right to do that'. 
The group agreed with the potential benefits and risks of peer-research and added their own views, which we integrated in our findings (Table 2). In regard to the our model of good practice in peer-research (Table 3), the group welcomed our effort and felt that this is a good starting point to further develop a framework which should also address crucial ethical issues such as justice, human rights, equality and tokenism.

\section{Discussion}

Peer-research with people with dementia is an innovative type of PPI which to date, has taken place only in qualitative research and has not yet been properly evaluated. We were able to retrieve only two studies reporting on the experience of peer-research in dementia, which may be further indication of the novelty of this type of research in this area. While accepting the limited quality of their evidence, we also included and drew on discussion papers to develop a preliminary model of practice (Table 3), which can be empirically evaluated and refined.

Given the limited literature, we decided to include in our review studies reporting on peerresearch with other populations, who may experience similar difficulties to people with dementia in being involved in peer-research, given the stigma attached to their condition (mental health service users), a shared experience of cognitive impairment (people with learning disabilities) or similar demographics (older people). We are aware that these populations have also a range of differences to people with dementia. For example, in general cognitive decline is an expected part of the process of dementia in contrast to the other groups (with the exception of older people with learning disabilities). So we suggest caution in interpreting our conclusions. However, the evidence from these studies can also inform good practice in peer-research in dementia. To the same extent, we feel that researchers working with other population groups may find it beneficial to integrate some of the principles of good practice that we highlighted in our review within their existing framework.

The lack of papers on the impact of working with peer-researchers is indicative of the challenge of evaluating a process that develops over a long period of time (Staley, 2009) and 
that given the complex interplay between researchers and peer-researchers, is difficult to measure meaningfully (Barber, 2008). Impact is also difficult to measure because there seems to be no consensus on what constitutes "positive impact". The conception of "positive impact" for academics may differ from and even be in conflict with that of peer-researchers. For academic researchers for example, a positive outcome could be "enhancing data collection", whereas for the peer-researchers it could be "offering support to fellow people with dementia". This makes impact assessment all the more challenging (and necessary).

The consultation with the EWGPWD confirmed our findings that in peer-research there are practical issues that need to be addressed by the academic research team in order to enable service users to become part of the process and support them to be confident and experienced enough to undertake the role of peer-researchers. These include appropriate research training for peer-researchers, involving academics who can work effectively with people with cognitive impairment, defining and negotiating research roles and budgeting for increased research costs.

All the studies reported some challenges in working with peer-researchers, in particular the risk that peer-researchers may not represent people with dementia. Although our studies did not report on how to address this challenge, the literature on peer-research with other populations, which is in a more advanced stage compared to peer-research in dementia, proposes a potentially effective strategy. In terms of how to select peer-researchers for example, in the field of intellectual disabilities it is common practice for academic researchers to hold presentation events about the research project (Burke et al., 2003; Grayson et al., 2013). In these events, the academic researchers can have informal chats and get to know potential peer-researchers, so that they can then make an informed selection process which mirrors the diversity of the population of people with intellectual disabilities. These events also represent a chance for the peer-researchers to assess whether the research project matches their interests and whether they wish to collaborate with the academic team. This mutual process of appraisal ensures that the selection process is mutual, as the decisional power is 
equally shared between the academic and the potential peer-researchers. We feel that a similar strategy can be used with peer-researchers with dementia in order to prevent the process of involvement from becoming tokenistic.

Another challenge that is reported in the papers is the potential power imbalance between academic and peer-researchers. Although the papers do not report directly any strategy on how to negotiate power, they offer general principles that the academic researchers can adopt in order to promote a climate of inclusion and equality among the peer-researchers. These principles include challenging traditional views on academic researchers being the repositories of knowledge and embracing the idea that peer-researchers can bring added value to research outputs. The democratisation of the research process seems best achieved in qualitative research, because the highly technical skills required in quantitative research may de facto discourage academic researchers to share control over the research process to peerresearchers.

Contrary to the practical challenges of peer-research, the ethical implications of this method were rarely reported in the studies and yet these represent a crucial aspect for people with dementia, as highlighted by the EWGPWD. We therefore urge that when working with peer researchers, academic researchers should not prioritise the practical elements of the process over issues related to human rights (e.g. autonomy and respect), justice and equality (e.g. the oportunities for people with dementia to be invited to participate in research) and tokenism (e.g.relevance of involving people with dementia from the begining of the research and not just in the process but also in the decision making for example around which areas of research should be prioritised).

\section{Conclusion}

Despite preliminary evidence about the positive impact of peer-research, there remains a need to empirically evaluate the associated costs and benefits of involvement, as it remains unclear whether being a peer-researcher impacts on the quality of life of the person living with 
dementia, whether it impacts on the quality of data and whether there are long-term benefits to the research community when peer-research is established within a research domain. In dementia research, it is academics who often establish research outcomes and how to measure them, based on their own set of values and on the research agenda rather than on the perspective of people with dementia. To counteract this imbalance, academics should consider whether involvement is meaningful for people with dementia. We suggest that planned evaluation of peer-research processes and outcomes, which will involve systematically obtaining the views of all stakeholder groups, is required to more fully understand the conditions needed when working with people with dementia as peerresearchers has the potential to add value to the field of dementia research.

Acknowledgements: We would like to thank the European Working Group of People With Dementia (EWGPWD) of Alzheimer Europe for their important contribution to the paper.

\section{Conflicting Interests: None.}

Ethical approval: None needed.

Description of authors' roles: Claudio Di Lorito developed the search strategy, searched for and appraised the literature, extracted and analysed data, developed the themes and contributed to the writing of the paper. Linda Birt helped in defining the search strategy, in appraising papers and contributed to the writing of the paper. Emese Csipke revised and commented on drafts. Martin Orrell helped capture nuances related to working with people with dementia and revised the drafts. Fiona Poland provided her expertise in aspects of PPI, as well as revising the draft. Dianne Gove and Ana Diaz-Ponce worked jointly on preparing the consultation with EWGPWD, moderated it, wrote up the consultation report and gave feedback on the final version of the paper. 


\section{References}

Barber, R. (2008). Can the impact of public involvement on health and social research be evaluated? An international Delphi study. Summary of findings. Sheffield: University of Sheffield.

Bartlett, R. (2014). Citizenship in action: the lived experiences of citizens with dementia who campaign for social change. Disability \& Society, 29, 1291-1304.

doi:10.1080/09687599.2014.924905

Burke, A., McMillan, J., Cummins, L., Thompson, A., Forsyth, W., McLellan, J. and Wright, D. (2003). Setting up participatory research: A discussion of the initial stages. British Journal of Learning Disabilities, 31, 65-69.

Clough, R., Green, B., Hawkes, B., Raymond, G. and Bright, L. (2006). Older people as researchers: Evaluating a participative project. York: Joseph Rowntree Foundation.

Dewing, J. (2002). From ritual to relationship: A person-centred approach to consent in qualitative research with older people who have a dementia. Dementia, 1, 157-171.

Downs, M. (1997). The emergence of the person in dementia research. Ageing and Society, 17, 597-607.

Frankham, J. (2009). Partnership Research: A Review of Approaches and Challenges in conducting Research in Partnership with Service Users. Swindon: ESRC National Centre for Research Methods.

Grayson, T., Hung Tsang, Y., Jolly, D., Karban, K., Lomax, P., Midgley, C., et al. (2013). Include me in: user involvement in research and evaluation. Mental Health and Social Inclusion, 17, 35-42.

Littlechild, R., Tanner, D. and Hall, K. (2015). Co-research with older people: perspectives on impact. Qualitative Social Work, 14, 18-35.

Miller, E. et al. (2006). Challenges and strategies in collaborative working with service user researchers: Reflections from the academic researcher. Research Policy and Planning, 24, $198-208$.

Moore, T. and Hollett, J. (2003). Giving voice to persons living with dementia: The researcher's opportunities and challenges. Nursing Science Quarterly, 16, 163-167.

Repper, J. et al. (2007). Carers of people with mental health problems as co-researchers: Reflections on the partnerships in Carer Assessment project (PICAP). In: M. Nolan et al., (Eds.) User Participation in Health and Social Care Research: Voices, Values and Evaluation (pp. 39-61). Maidenhead: Open University Press.

Rose, D. (2003). Collaborative research between users and professionals: peaks and pitfalls. Psychiatric Bulletin, 27, 404-406.

Scottish Dementia Working Group Research Sub-Group (2014). Core principles for involving people with dementia in research: Innovative practice. Dementia, 13, 680-685. 
Staley, K. (2009). Exploring Impact: Public Involvement in NHS, Public Health and Social Care Research. Eastleigh: INVOLVE.

Tanner, D. (2012). Co-research with older people with dementia: Experience and reflections. Journal of Mental Health, 21, 296-306.

Turner, M., and Beresford, P. (2005). User Controlled Research: Its Meanings and Potential. Final Report. Eastleigh: INVOLVE.

Walmsley, J. (2004). Involving users with learning difficulties in health improvement: lessons from inclusive learning disability research. Nursing Inquiry, 11, 54-64.

Wilkinson, H. (2002). Including people with dementia in research: Methods and motivations. In H. Wilkinson, (Eds.) The perspectives of people with dementia - research methods and motivations (pp. 9-24). London: Jessica Kingsley.

Wilkinson, H., and Hubbard, G. (2003). Exploring innovative ways of seeking the views of older people in health and social care research. Research, Planning and Policy, 21, 1-4. 
Figure 1. Selection of papers.

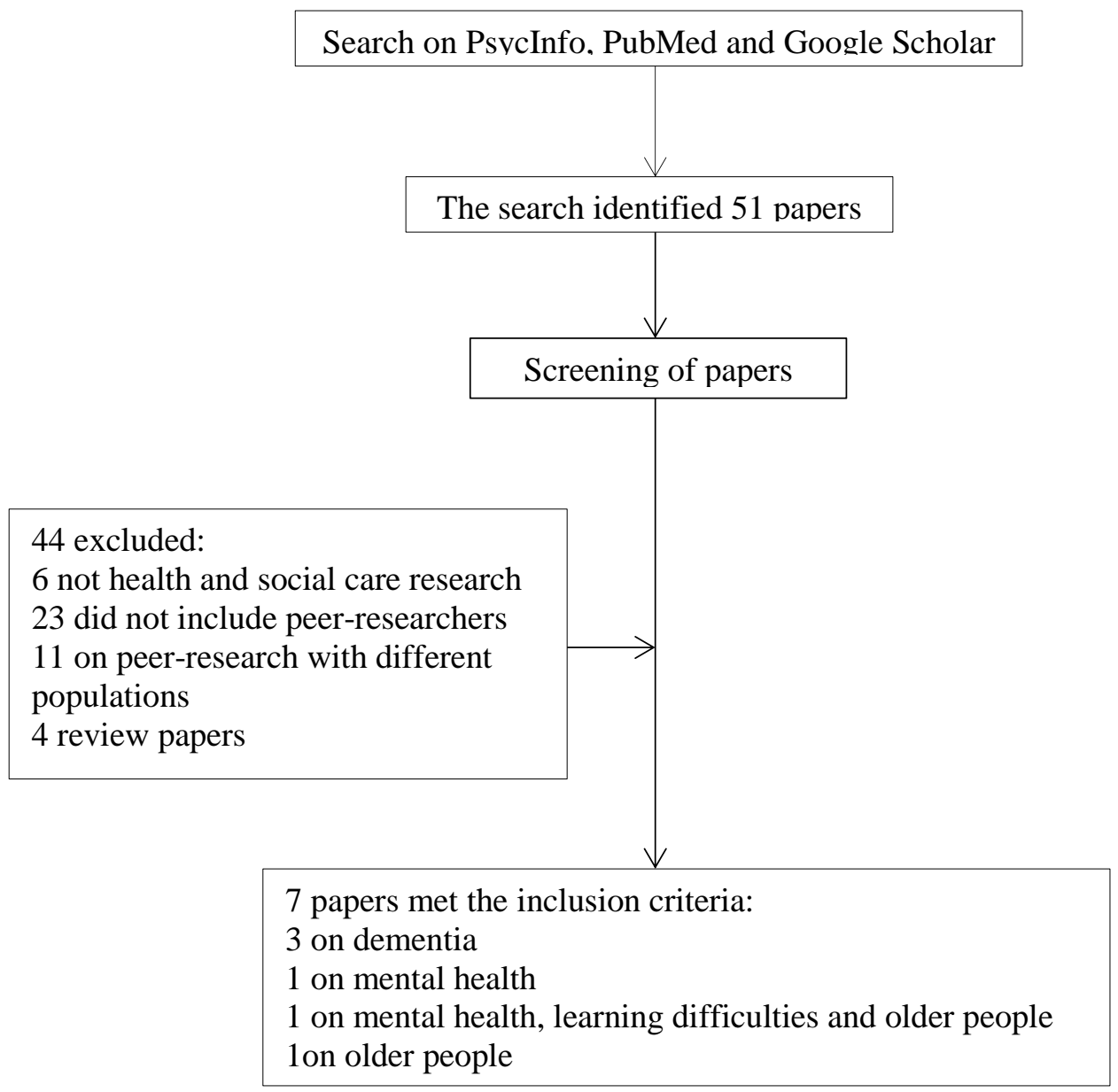


Table 1. Study characteristics and main findings.

\begin{tabular}{|l|l|l|l|}
\hline Author, year & Type of study & Peer-researcher population & Main Findings \\
\hline Rose, 2003 & $\begin{array}{l}\text { A discussion paper which reports } \\
\text { the outcomes from two studies } \\
\text { which involved service users of } \\
\text { mental health services. }\end{array}$ & Mental Health Service users & $\bullet$ Power differentials exist in career, salary and status \\
\hline $\begin{array}{l}\text { Walmsley, } \\
2003\end{array}$ & $\begin{array}{l}\text { A discussion paper outlining the } \\
\text { elements of inclusive learning } \\
\text { disability research. }\end{array}$ & People with learning disabilities & $\bullet \quad$ Clarity over roles and expectations is crucial \\
\hline $\begin{array}{l}\text { Clough et al., } \\
2006\end{array}$ & $\begin{array}{l}\text { A report involving 22 older } \\
\text { people describing their } \\
\text { experiences of being peer } \\
\text { researchers in all aspects of a } \\
\text { large project }\end{array}$ & Older people & - Academics should carry out tasks that need technical skills \\
\hline Miller, 2006 & $\begin{array}{l}\text { An evaluation of the experience } \\
\text { of working with peer-researchers } \\
\text { from three organisations in a } \\
\text { study evaluating services. }\end{array}$ & $\begin{array}{l}\text { Three service users' groups: } \\
\text { Older people, people with } \\
\text { learning difficulties and mental } \\
\text { health service users }\end{array}$ & Realistic goals need to be set \\
\hline
\end{tabular}




\begin{tabular}{|c|c|c|c|}
\hline Tanner, 2012 & $\begin{array}{l}\text { An evaluation of the experience } \\
\text { of three people living with } \\
\text { dementia working as peer- } \\
\text { researchers in a project exploring } \\
\text { older people's experience of } \\
\text { transitions into or between } \\
\text { dementia services }\end{array}$ & People with Dementia & $\begin{array}{l}\text { - } \quad \text { Training allows familiarisation between researchers } \\
\text { - } \quad \text { Visual prompts are useful as memory aids } \\
\text { - } \quad \text { Importance of pre and post-interview meetings } \\
\text { - } \quad \text { Matching personalities may help the interview sessions } \\
\text { - } \quad \text { Peer-research nurtures relaxed atmosphere and emotional connection } \\
\text { - } \quad \text { Peer-research promotes positive dementia identity } \\
\text { - } \quad \text { It promotes social networking } \\
\text { - } \quad \text { It provides a unique window into world of dementia }\end{array}$ \\
\hline $\begin{array}{l}\text { Scottish } \\
\text { Dementia } \\
\text { Group, } 2014\end{array}$ & $\begin{array}{l}\text { A discussion paper outlining the } \\
\text { result of a project with people } \\
\text { with dementia to identify their } \\
\text { priorities when being involved in } \\
\text { research }\end{array}$ & People with Dementia & $\begin{array}{l}\text { - } \text { Collaborative effort is crucial } \\
\text { - } \text { Guaranteeing health and safety of peer-researchers } \\
\text { - } \quad \text { Simplicity in language is crucial } \\
\text { - } \quad \text { Personalisation of training for peer-researchers } \\
\text { - } \quad \text { Full-involvement is preferable } \\
\text { - } \quad \text { Time and memory issues require proper addressing }\end{array}$ \\
\hline
\end{tabular}




\begin{tabular}{|c|c|c|c|}
\hline $\begin{array}{l}\text { Littlechild, } \\
\text { Tanner \& } \\
\text { Hall, } 2015\end{array}$ & $\begin{array}{l}\text { An empirical evaluation of peer- } \\
\text { research in a project on older } \\
\text { people's experience of dementia } \\
\text { services }\end{array}$ & Older people & $\begin{array}{l}\text { - } \text { Giving up power may be difficult for academic researchers } \\
\text { - } \quad \text { Peer-researchers may not represent people with dementia } \\
\text { - } \quad \text { Time and place are key aspects of sensible involvement } \\
\text { - } \quad \text { Additional costs are inevitable } \\
\text { - } \quad \text { Peer-researchers may not address research questions } \\
\text { - } \quad \text { Peer-researchers facilitate opening up, recruitment rates } \\
\text { - } \quad \text { Peer-research may promote a positive dementia identity }\end{array}$ \\
\hline
\end{tabular}


Table 2. Potential benefits and challenges of peer-research with people with dementia.

\begin{tabular}{|c|c|c|c|c|}
\hline \multirow[t]{2}{*}{ Population } & \multicolumn{2}{|c|}{ Potential benefits } & \multicolumn{2}{|c|}{ Potential challenges } \\
\hline & What we found & What the EWGPWD added & What we found & What the EWGPWD added \\
\hline Peer-researchers & $\begin{array}{ll}\text { - } & \text { Feeling they are } \\
& \text { contributing to change } \\
\text { - } & \text { Relocation within the } \\
& \text { social sphere } \\
\text { - } & \text { Reduced stigma } \\
\text { - } & \text { Reduced isolation }\end{array}$ & $\begin{array}{ll} & \text { Owning research } \\
\text { - } & \text { Challenging own views } \\
\text { on research } \\
\text { - } \\
\text { banaging dementia } \\
\text { better }\end{array}$ & $\begin{array}{ll}\text { - } & \text { Emotional overburden } \\
\text { - } & \text { Perceived power } \\
\text { differential }\end{array}$ & $\begin{array}{ll}\text { - } & \text { Difficulty in conforming to } \\
\text { protocol } \\
\text { - } & \text { Difficulty interpreting what } \\
\text { participants say } \\
\text { - } & \text { Difficulty responding } \\
\text { appropriately to participants } \\
\text { - } & \text { Difficulty understanding } \\
\text { technical language }\end{array}$ \\
\hline Academic researchers & $\begin{array}{l}\text { Better understanding } \\
\text { experience of living } \\
\text { with dementia }\end{array}$ & $\begin{array}{l}\text { - Challenging wariness } \\
\text { toward people with } \\
\text { dementia }\end{array}$ & - Relinquishing power & \\
\hline Research participants & $\begin{array}{ll} & \text { Feeling more } \\
\text { comfortable to open } \\
\text { up }\end{array}$ & $\begin{array}{ll}- & \text { Reduced stigma } \\
\text { - } & \text { Feeling more understood } \\
\text { given shared lived } \\
\text { experience }\end{array}$ & & $\begin{array}{l}\text { Becoming distressed by } \\
\text { comparing own skills to the peer- } \\
\text { researcher's }\end{array}$ \\
\hline Research project & $\begin{array}{ll}\text { - } & \text { Boosting recruitment } \\
\text { rates } \\
\text { - } & \text { Enriched data and } \\
\text { research output }\end{array}$ & $\begin{array}{l}\text { - } \begin{array}{l}\text { Provide insight into } \\
\text { dementia world }\end{array} \\
\text { - } \\
\text { Facilitated data } \\
\text { collection given shared } \\
\text { language } \\
\text { - } \text { Generating new } \\
\text { knowledge } \\
\text { - Addressing what is } \\
\text { relevant for people with } \\
\text { dementia }\end{array}$ & $\begin{array}{l}\text { - Sample may be not } \\
\text { representative of people } \\
\text { with dementia } \\
\text { - } \quad \text { Extra resources }\end{array}$ & 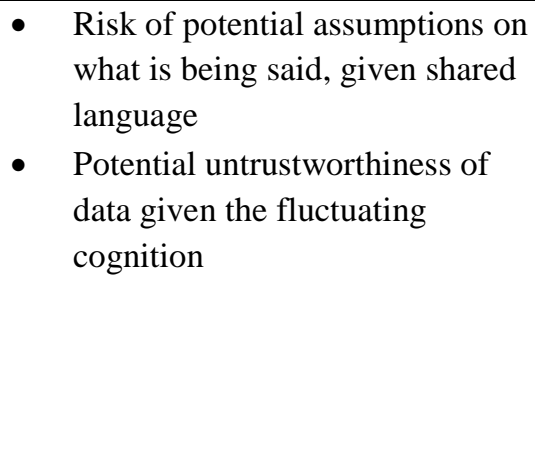 \\
\hline
\end{tabular}


Table 3. A model of good practice in peer-research with people with dementia.

\begin{tabular}{|c|c|c|c|}
\hline \multirow[t]{2}{*}{ Activity } & \multirow[t]{2}{*}{ Goal to be achieved } & \multicolumn{2}{|c|}{ How to achieve the goal } \\
\hline & & What we found & What the EWGPWD added \\
\hline Training & $\begin{array}{l}\text { - } \text { Build research skills } \\
\text { - } \quad \text { Develop confidence } \\
\text { Become aware of own strengths } \\
\text { and limits } \\
\text { - Understand research }\end{array}$ & $\begin{array}{l}\text { - } \quad \text { Training sessions, which are } \\
\text { personalised in nature }\end{array}$ & $\begin{array}{l}\text { - } \quad \text { Training should be on research } \\
\text { skills and on project } \\
\text { - } \quad \text { Sessions should be short and } \\
\text { regularly repeated } \\
\text { - } \quad \text { Sessions should focus on } \\
\text { practical scenarios. }\end{array}$ \\
\hline $\begin{array}{l}\text { Defining involvement extent } \\
\text { and research roles }\end{array}$ & - Enhance research & $\begin{array}{l}\text { - } \begin{array}{l}\text { Acknowledge limitations of cognitive } \\
\text { impairment }\end{array} \\
\text { - Be realistic } \\
\text { - Open discussion about roles within } \\
\text { the team }\end{array}$ & $\begin{array}{l}\text { - Acknowledge own limitations } \\
\text { that could negatively impact } \\
\text { research }\end{array}$ \\
\hline $\begin{array}{l}\text { Working with cognitive } \\
\text { impairment }\end{array}$ & $\begin{array}{l}\text { - Counteract the potential impact of } \\
\text { cognitive impairment }\end{array}$ & $\begin{array}{l}\text { - Use simple/practical/clear language } \\
\text { - } \quad \text { Develop visual prompts } \\
\text { - } \quad \begin{array}{l}\text { Hold pre and post-interview } \\
\text { discussions between researchers }\end{array} \\
\text { - } \quad \begin{array}{l}\text { Refresh questions before interview } \\
\text { session }\end{array} \\
\text { - Favour a familiar setting to hold } \\
\text { interviews } \\
\text { - Make counselling available }\end{array}$ & $\begin{array}{l}\text { - } \quad \text { Give extra time } \\
\text { - } \quad \text { Provide assistance and support }\end{array}$ \\
\hline
\end{tabular}




\begin{tabular}{|l|r|rl|}
\hline $\begin{array}{l}\text { Considering resource } \\
\text { implications }\end{array}$ & $\bullet$ Pursue high quality research & $\bullet$ & Invest money into training \\
& & $\begin{array}{l}\text { Financially compensate peer- } \\
\text { researchers }\end{array}$ \\
& $\bullet$ & Refund travel expenses \\
& & $\bullet$ & Pay for support workers \\
\hline
\end{tabular}

